\title{
WestVirginiaUniversity.
}

Department of Economics

Working Paper Series

\section{Professional Sporting Events and Traffic: Evidence from US Cities}

Brad R. Humphreys

Hyunwoong Pyun

Working Paper No. 17-05

This paper can be found at the College of Business and Economics Working Paper Series homepage: 


\title{
Professional Sporting Events and Traffic: Evidence from US Cities
}

\author{
Brad R. Humphreys* \\ West Virginia University
}

\author{
Hyunwoong Pyun ${ }^{\dagger}$ \\ West Virginia University
}

March 25, 2017

\begin{abstract}
Sporting events concentrate people at specific locations on game day. No empirical evidence currently exists linking sporting events to local traffic conditions. We analyze urban mobility data from 25 US metropolitan areas with MLB teams over the period 1990 to 2014 to assess the relationship between local traffic and Major League Baseball (MLB) games. Instrumental variable regression results indicate MLB attendance causes increases in local vehicle-miles traveled. At the sample average attendance of 2.8 million, average daily vehicle-miles traveled increases by about $6.9 \%$ in cities with MLB teams. Traffic congestion increases by $2 \%$, suggesting that MLB games generate congestion externalities.
\end{abstract}

Keywords: transportation, traffic congestion, vehicle-miles traveled, Major League Baseball JEL Codes: Z20, R41, R23

\section{Introduction}

The presence of a professional sports team in a city can have a substantial impact on local economic activity. Previous research focused primarily on assessing the tangible or intangible benefits of professional sports teams in the local economy; relatively little focused on the direct and indirect costs generated by professional sports teams, facilities, and the games played in these facilities. Because of the large public subsidies provided for the construction and operation of professional

\footnotetext{
${ }^{*}$ We thank Brian Soebbing and participants at the 2016 Southern Economic Association Conference for valuable comments. West Virginia University, College of Business \& Economics, Department of Economics, 1601 University Ave., PO Box 6025, Morgantown, WV 26506-6025, USA; Email: brhumphreys@mail.wvu.edu.

${ }^{\dagger}$ West Virginia University, College of Business \& Economics, Department of Economics, 1601 University Ave., PO Box 6025, Morgantown, WV 26506-6025, USA; Email: hypyun@mix.wvu.edu.
} 
sports facilities, a research on costs associated with professional sports is potentially important. A thorough understanding of both benefits and costs of professional sports teams provides and important context for understanding the subsidies provided to professional sports teams.

Most of the existing research on economic costs associated with professional sports focuses on either financial costs associated with facility construction or crime associated with events held in facilities. Pyun and Hall (2016) review the existing evidence on the relationship between professional sporting events and crime. Little research focused on direct costs generated by games like public safety, sanitation, or indirect costs like the opportunity cost of funds used to subsidize the construction and operation of these facilities. In this paper focuses on the relationship between professional sports events and traffic congestion, another overlooked cost of hosting sporting events.

Traffic congestion represents a significant problem in many urban areas. Duranton and Turner (2011) note that in 2001, the average American household spent more than 2.5 person-hours each day in a passenger vehicle and investigate the effects of road building and other factors on congestion. Rappaport (2016) extends the standard monocentric city model to include commuting and identifies traffic congestion as a critical factor constraining local growth. Krueger et al. (2009) conclude that commuting to and from work are among urban household's least enjoyable activities, suggesting that additional time spent in a car at the end of the day involves substantial psychic and time costs. Holian and Kahn (2012) investigate the relationship between urban vibrancy, traffic congestion and greenhouse gas emissions; the presence of a professional sports team in a city could represent a type of consumer amenity that contributes to urban vibrancy.

Professional sporting events concentrate large numbers of fans attending games in a small area at the same time. The presence of large surface parking lots and parking structures near sports facilities indicates that large numbers of fans drive to games. Many professional sporting events take place on weekday evenings, and many sports facilities are located in the urban core of large cities. Taken together, this suggests that sporting events could have a substantial impact on traffic congestion.

We empirically analyze the relationship between attendance at Major League Baseball (MLB) games and traffic in US metropolitan areas. MLB represents an ideal setting for assessing the relationship between attendance at sporting events and vehicle traffic. MLB teams typically play 81 home games per season and these games are distributed across all days of the week. Weekday 
MLB games occur primarily at night, with typical start times of $6 \mathrm{pm}$ to 8pm. This timing means that some fans attending games will be driving to the game during the evening rush hour. In addition, many MLB stadiums are located in the downtown area of cities. We analyze traffic data compiled by the Texas A\&M University Transportation Institute that are constructed as part of the 2015 Urban Mobility Scorecard (UMS). The UMS provides annual estimates of traffic and congestion for US metropolitan areas. The aggregate annual estimates of vehicle miles traveled and congestion are based on detailed micro data from the Federal Highway Administrations Highway

Performance Monitoring System (HPMS) that are highly disaggregated over space (at the level of individual segments of roads) and time (measured at hourly intervals).

We estimate reduced form empirical models explaining variation in vehicle-miles traveled (VMT) for 25 large US metropolitan areas with MLB teams over the period 1990-2014. The empirical models control for MSA population and economic conditions, stadium location, and include MSA and year fixed effects to control for unobservable heterogeneity in factors affecting local VMT. Instrumental variables estimates indicate that each additional 1,000 persons attending an MLB game was associated with 1.7 additional average daily vehicle-mile traveled (DVMT) in the host city. For an MLB team drawing 2.8 million fans in a season, this represents an increase of about $6.9 \%$ in DVMT in a metropolitan area. Note that this increase in traffic delay time affects all vehicle occupants in the metropolitan area, not just fans attending MLB games. Fans attending MLB games increase VMT in metropolitan areas. This increase in VMT has implications for traffic congestion, wear and tear on roads, and greenhouse gas emissions that affect the climate.

\section{Sports and Traffic}

Fan attendance represents the key link between sporting events and urban traffic. To attend a sporting event, most fans travel between their home or place of work and the venue where the event takes place. Fan attendance at professional sporting events concentrates economic activity spatially in and around facilities and temporally on game day. This concentration has clear economic impacts. Humphreys and Zhou (2015) develop a spatial economic model that includes agglomeration effects stemming from increased fan activity in and around professional sports facilities on game day that predicts the presence of a pro sports team will increase nearby property values and induce other 
service providing firms to co-locate near the sports facility. Huang and Humphreys (2014) develop evidence of increased housing market activity near new sports facilities after they open, supporting the predictions of this model. If this housing market activity reflects in-migration of new residents, the population density near sports facilities will increase. Coates and Humphreys (2003) show that employees in the amusements and recreation industry - the industry containing athletes and other employees working in sports facility - earn more in cities with professional sports teams than employees in this industry in cities without professional sports teams; these results support the idea of increased economic activity in and near sports facilities. Despite this evidence of increased economic activity near sporting events, no evidence exists supporting the idea that professional sports teams or facilities generate broader economic benefits across metropolitan areas (Coates et al., 2008).

The concentration of fans around sports facilities on game day, and increases in nearby residents year round, has clear consequences for traffic near sports facilities. Most professional sports facilities are located in or near the Central Business District, which also contains many firms employing large numbers of workers who travel to and from their residence on weekdays, often by car. Many fans drive to games and park in dedicated lots surrounding sports facilities or in nearby lots and parking structures that are also used by local workers and residents.

A few papers in the geography literature examined the effect of sports facilities on local parking and traffic. All are case studies and most use surveys of local residents to assess the extent to which increased traffic, parking, crowds, and noise on game days are perceived as a "nuisance" externality by local residents. Humphreys et al. (1983) assessed the importance of negative externalities generated by games played in a football stadium in Southampton, England using household surveys; this paper concluded that traffic and parked cars generated substantially larger "nuisance" externalities on game day than crowds or noise, and the negative effects of traffic and parking extended several miles from the stadium. Chase and Healey (1995) assessed the importance of negative externalities generated by games and rock concerts in a football stadium in Ipswich, England; this paper also concluded that traffic and parked cars were the largest "nuisance" externalities associated with football matches, and found a similarly large traffic impact area. Chase and Healey (1995) discussed proposed stadium location decisions in Australia in light of the existing transportation environment around several rugby and Australian Rules Football stadiums located in the center of 
larger Australian cities and Australian transportation policy initiatives. Although this paper did not develop empirical evidence, the discussion highlights the importance of increased local traffic and parking on game day.

Case-study based evidence clearly indicate that additional traffic around sports facilities on game day represent an important "nuisance" externality to residents of areas near stadiums in England and Australia. The existing theoretical and empirical evidence on the spatial economic of professional sports teams in North America suggests that stadiums and arenas concentrate fans and economic activity in and near sports facilities on game day, and may also increase the number of businesses and residents near sports facilities. All these factors could increase traffic. However, the perceptions of residents near sports facilities about traffic conditions on game day may not reflect outcomes across a metropolitan area, and concentration of fans and economic activity near a sports facility may not increase overall traffic in a metropolitan area. A full understanding of the potential impact of sporting events on traffic in a metropolitan area requires a model of the determination of realized driving outcomes.

\section{Determination of Vehicle Miles Traveled}

Duranton and Turner (2011) develop a model of the equilibrium determination of vehicle miles traveled in a city. In this model, a city has road lane miles $R$ and vehicle miles traveled (VMT) on these roads over some specific time period $Q$. Both consumers and businesses demand driving in the city, which depends on the effective price of driving $P$. This effective price of driving includes direct and indirect vehicle operation costs like gas, vehicle maintenance, and insurance, and the time and opportunity cost of driving. The inverse demand curve for VMT, $P(Q)$, slopes down; as the price of driving falls, firms and households drive more miles, other things equal. Other factors unrelated to the price of driving, like business cycle conditions, weather, changes in the price of substitutes or compliments to driving, and increased demand for consumer goods and services that require driving in order to consume, like sporting events, will shift the city's demand curve for driving.

The supply curve for driving in a city depends on the roads in the city and the cost of driving. Duranton and Turner (2011) posit a total variable cost function for VMT, $C(R, Q)$ that depends 
on the existing stock of roads, $R$ and the distance driven by drivers in the city, $Q$. All drivers in the city face the same average cost of driving in equilibrium. Holding lane-miles of road constant in the city, the average cost of driving, $A C(R)$, must increase as VMT increases, thus the supply curve for driving is upward sloping. This result is widely recognized in the transportation economics literature (Small and Verhoef, 2007).

Figure 1: Supply, Demand, and Equilibrium VMT

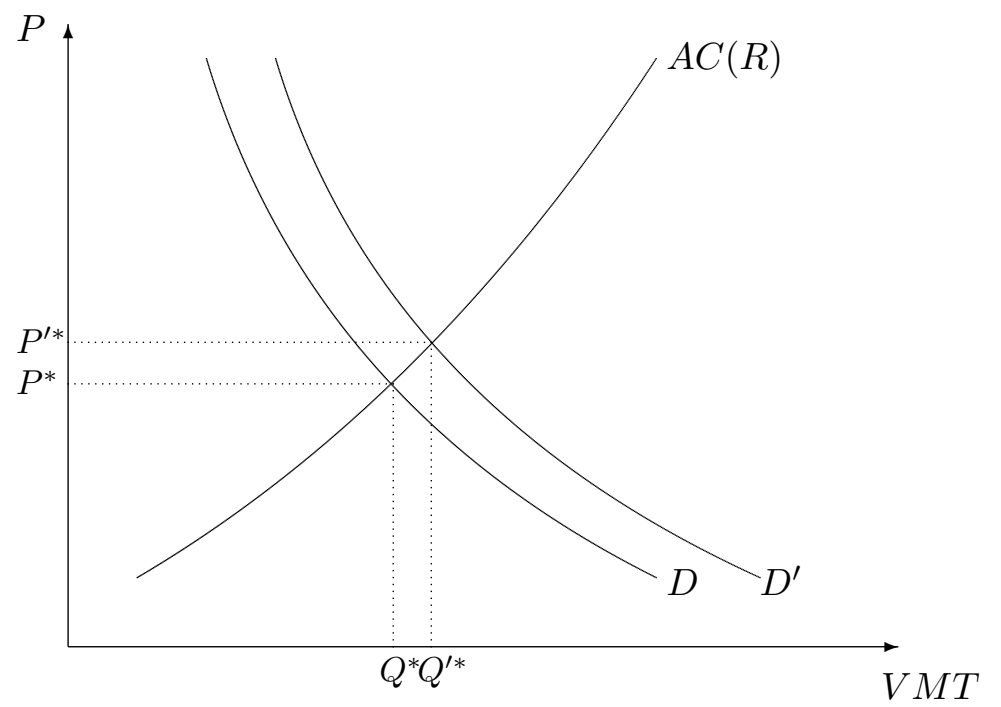

Given demand and supply curves for driving in a city, and a specific quantity of roads, equilibrium VMT in a city is $Q^{*}$, as shown on Figure 1. Duranton and Turner (2011) focus on changes in the supply of road-lane miles in a city, which shifts the supply curve for driving to the right as more roads are built, increasing equilibrium VMT in the city. Here, we focus on short run changes in the local economy that shift the demand curve for driving to the right, as shown on Figure 1. This shift in the demand curve for driving also increases equilibrium VMT in the city from $Q^{*}$ to $Q^{\prime *}$.

Other models emphasize the importance of residential location choice and commuting to work as an important determinant of urban driving decisions. Albouy and Lue (2015) develop a model of household choice of residence location, and firm choice of location, that makes predictions about length of commute in a standard urban monocentric city model. However, households also drive to shop, consumer entertainment activities, and engage in other non-work related trips. The model developed by Duranton and Turner (2011) is more general, in that total VMT in a city is explained, 
rather than commuting VMT.

This model of equilibrium determination of VMT provides a useful framework for motivating our empirical work. How might professional sporting events affect equilibrium VMT in a city? Suppose that all fans attending a sporting event drive to the stadium from their residence to watch the game, and these round-trips represent new driving that would not have taken place if the fan did not attend the sporting event. In this case, attending the sporting event increases demand for driving in the city, shifting the demand curve from $D$ to $D^{\prime}$, as shown on Figure 1 . If these fans live outside the area where the facility is located, then traffic congestion will increase in the area around the facility, and potentially traffic in other residential areas of the city.

Alternatively, suppose that all fans drive from their residence to the facility to watch games, but these round-trips to and from the facility replace other trips in the area that would have been taken for other reasons. In this case, total local demand for driving is unchanged, the demand curve for VMT does not shift, and equilibrium VMT, $Q^{*}$ does not change. This case represents "displacement" of VMT within a city. However, traffic congestion near the facility would still increase in this case, since fan travel to the sports facility would not have occurred in that area absent the sporting events.

Another case arises when fans work in the area where the sports facility is located, drive to the area at the beginning of the day and park, walk from their place of employment to the facility, and then drive home after the game ends. To the extent that fans engage in this type of behavior, demand for VMT does not increase, since no new driving takes place despite attendance at the sporting event. As more fans engage in this form of travel to games, the demand curve for VMT shifts less, and equilibrium VMT in the city remains unchanged. This case could be associated with less congestion near the facility, since employees attending the game do not drive home during the evening rush hour, but instead shift their evening drive home to the post-game period.

Another possibility is fans taking some form of public transportation (bus, light rail, train, subway) to games. If public transportation is a substitute for driving, then any fans taking public transportation to games would decrease demand for driving in the city, reducing equilibrium VMT. However, Duranton and Turner (2011) conclude that the presence of public transportation has no effect on equilibrium VMT in cities. Increased use of public transportation by some residents simply encourages additional driving by others. Based on this result, we do not focus on public 
transportation options in our analysis of the relationship between VMT and sporting events.

This model provides guidance for our empirical analysis. The model shows that our empirical specification must include variables that shift the demand curve for driving and also control for the supply of roads in metropolitan areas. Absent detailed data about how individual fans travel to games, the presence of sporting events could increase VMT, or have no effect on VMT, depending on the type of travel decisions made by individuals attending games.

Previous research on the determinants of metropolitan VMT identifies a number of local factors that affect traffic volume. Salon et al. (2012) review the empirical literature on determinants of VMT and show that factors like residential density, land use patterns, road and parking pricing, public transport, and workplace-based programs like telecommuting affect VMT. Road pricing, in the form of 5 to 10 cent per-mile peak-time congestion charges on a small number of roads reduced VMT by $10 \%$ to $15 \%$ in Portland and Sacramento; voluntary employer-based programs to reduce commuting trips reduced VMT by $5 \%$ to $6 \%$ and marketing programs aimed at reducing single-occupance vehicle use reduced VMT by $9 \%$ to $12 \%$.

A substantial literature analyzing the effect of short-run macroeconomic conditions on fatal car crashes exists (Cotti and Tefft, 2011; He, 2016). This literature demonstrates that VMT varies with short-run local macroeconomic conditions. This highlights the importance of controlling for variation in local economic conditions on VMT. If factors like business cycles, congestion pricing on limited local roads, and marketing programs affect VMT, it is certainly possible that attendance at sporting events, especially MLB games which draw large numbers of fans to specific parts of cities on 50 to 60 weeknights per year, could affect VMT in cities.

\section{Empirical Analysis}

Following Duranton and Turner (2011), we estimate empirical models of annual VMT in US metropolitan areas. These empirical models include variables reflecting factors that affect demand and supply for driving. Attending professional sporting events is one factor that affects demand for driving in US metropolitan areas. Estimating these models requires data on VMT, road lane-miles, economic and demographic factors that affect demand for driving, and attendance at sporting events. 


\section{Data Description}

Metropolitan area traffic data come from the 2015 Urban Mobility Scorecard (UMS). ${ }^{1}$ We use total annual hours of delay as a traffic congestion measure, and daily average vehicle-miles traveled (DVMT) as an equilibrium traffic demand and supply measure. The daily vehicle-miles traveled data are constructed by aggregating information from individual roadway sections at an hourly frequency for a large number of roadway segments in metropolitan areas. An individual roadway segment typically contains from 0.5 to 1 miles of roadway. Individual roadway segment DVMT are calculated by multiplying average daily traffic (in terms of vehicle counts) and road miles on each roadway section.

The total annual hours of traffic delay is estimated by comparing the ratio of actual speed to free-flow speed on each roadway section to daily vehicle miles. Lasley et al. (2014) describe the method used to estimate annual hours of traffic delay in metropolitan areas.

Raw micro level data underlying the UMS DVMT data come from the US Department of Highways' Highway Performance Monitoring System (HPMS). Traffic speed data are from INRIX, a company that collects urban traffic data. Annual data on the total road miles in each metropolitan area, a measure of the supply of roadways, come from the HPMS.

Metropolitan area population estimates and unemployment rates in each year come from the US Census Bureau, Bureau of Labor Statistics. Annual MLB team attendance data were collected from daily box scores in baseball-reference.com. We include attendance at postseason and regular season games in the MLB attendance variables.

We construct two stadium location variables to control for stadium location and existing commuting-related traffic congestion. First, we identify stadiums located in the Central Business District (CBD) of each metropolitan area using the CBD definition from the 1982 Census of Retail Trade (Bureau of the Census, 1985). CBDs contain high concentrations of retail and service businesses and "high traffic flow" was one criteria used to identify CBDs. Given this, MLB stadiums located in or near CBDs may experience higher traffic volume for reasons unrelated to games played. The 1982 Census of Retail Trade defined the CBD for each US MSA by listing specific streets which formed the boundary of the CBD. Based on this definition, we generate a

\footnotetext{
${ }^{1}$ This data set is constructed by the Texas A\&M University Transportation Institute and available at https://mobility.tamu.edu/ums/
} 
dummy variable which is equal to 1 for MLB stadiums located in the CBD. For a stadium located outside of the CBD, we measure the driving distance from the nearest boundary of the CBD tot he stadium, as many stadiums are located just outside of the CBD; 14 stadiums are located less than 1 mile from the nearest boundary of the CBD. Also, the most recent definition of the CBD, from 1982 , is old so there is a chance that the CBD has grown over time and now includes these nearby stadiums. We assume that the distance variable will capture this heterogeneity among stadiums located just outside the 1982 CBD.

The 2015 Urban Mobility Scorecard contains data from 101 metropolitan areas but only 25 are used in our analysis to address possible selection problem which are discussed below. The sample period includes the annual data from 1990 to 2014. Although the raw traffic congestion data are available from 1982, MSA level unemployment rates data are only available after 1990.

Summary statistics are shown on Table 1. The total annual hours of traffic delay in metropolitan areas in the sample is 50,876,000 hours, on average. Average DVMT is about 29 million miles with about half those miles driven on freeways and half on arterial streets. The average metropolitan area in the sample has about 5,700 miles of roadway. Large cities usually have higher population density and more traffic, so all traffic measures are larger in large cities. The same argument can be applied to explain the difference in annual traffic delays between cities with and without MLB teams. MLB teams are located in large cities, so all traffic volume and congestion measures are larger in cities with MLB teams. About a quarter of MLB stadiums are located in the CBD, and the average distance from the CBD for the stadiums outside of the CBD is 1.75 miles.

Total metropolitan population varies from around 260,000 (Anchorage, AK, 1990) to over 19 million (New York, 2014). In 1999 Raleigh, NC had the lowest unemployment rate (1.5) while in 1990 McAllen, TX had the highest (22.4). Annual MLB attendance by MSA also varies from around 800,000 (Miami, 2002) to 8,340,000 (New York, 2008). Note that we sum annual MLB attendance across teams if a metropolitan area has more than one MLB team. For example, annual MLB attendance in New York is the sum of attendance for both the Mets and the Yankees. 
Table 1: Summary statistics

\begin{tabular}{|c|c|c|c|c|c|c|}
\hline & \multicolumn{2}{|c|}{ Full Sample } & \multicolumn{2}{|c|}{ no MLB team } & \multicolumn{2}{|c|}{ MLB team in MSA } \\
\hline & Mean & S.D. & Mean & S.D. & Mean & S.D. \\
\hline Average daily vehicle-miles traveled (000) & 29383 & 37907 & 14303 & 9408 & 70728 & 552945 \\
\hline Total annual hours delay $(000)$ & 50876 & 85747 & 21128 & 19142 & 132430 & 132082 \\
\hline Interstate daily vehicle-miles traveled (000) & 14642 & 19648 & 6881 & 5109 & 35919 & 27489 \\
\hline Arterial daily vehicle-miles traveled (000) & 14741 & 18687 & 7421 & 4749 & 34808 & 26378 \\
\hline MSA Population (000) & 2039 & 2613 & 1060 & 676 & 4723 & 3804 \\
\hline MSA unemployment rate & 5.96 & 2.51 & 6.02 & 2.69 & 4.57 & 2.93 \\
\hline MSA total road miles & 5777 & 6249 & 3133 & 1614 & 13028 & 8203 \\
\hline Annual MLB attendance & 755766 & 1443059 & - & - & 2827696 & 1390079 \\
\hline Stadium in CBD & 0.067 & 0.25 & - & - & 0.25 & 0.43 \\
\hline Distance from CBD & 0.47 & 1.57 & - & - & 1.75 & 2.65 \\
\hline Observations & 2200 & & 1612 & & 588 & \\
\hline
\end{tabular}

\section{Empirical Model}

Following Duranton and Turner (2011), the basic empirical specification is a reduced form equation for annual traffic outcome measures in metropolitan areas

$$
Y_{i t}=\alpha_{i}+\beta M L B a t t_{i t}+\gamma^{\prime} X_{i t}+\lambda_{t}+u_{i t}
$$

where $Y_{i t}$ is a traffic outcome measure for metropolitan area $i$ in year $t$. We use both average DVMT and annual hours of traffic delay as dependent variables. $\alpha_{i}$ and $\lambda_{t}$ capture metropolitan area fixed effects and year fixed effects, respectively. $X_{i t}$ is a vector of control variables which affect demand and supply for driving in metropolitan areas and vary over time and across metropolitan areas. This vector includes annual MSA population, the MSA unemployment rate, and total road lane-miles in the metropolitan area which reflects the supply of roads in each metropolitan area. Duranton and Turner (2011) demonstrate the importance of controlling for roadway supply when explaining variation in DVMT. $X_{i t}$ also includes the stadium location variables. While many MLB stadiums are located in the city center, either in the CBD or just out of the CBD, some other stadiums are located in the suburbs and this variation in stadium location might systematically affect traffic. To control for this heterogeneity, we include a dummy variable identifying stadiums located in the $\mathrm{CBD}$, and the driving distance from the $\mathrm{CBD}$ to the stadium for stadiums located outside the CBD. $u_{i t}$ is a mean zero, possibly heteroscedastic random error term capturing all other factors that affect traffic outcomes in metropolitan areas. 
$M L B a t t_{i t}$ reflects annual attendance at MLB games in metropolitan area $i$ in year $t$. We assume this variable potentially shifts demand for driving in the metropolitan area. Note that this attendance data is at the metropolitan area level, so we sum attendance across all MLB teams in metropolitan areas has multiple teams. In this model, $\beta$ captures the effect of attendance at MLB games on traffic congestion in the host city. This is the parameter of interest in this empirical model.

When estimating $\beta$, an endogeneity concern stemming from correlation between MLB attendance and unobservable factors affecting traffic arises from two sources. First, the existence of unobserved heterogeneity in road configuration, weather, or terrain in a metropolitan area with a MLB team might generate biased estimates of $\beta$. To address this problem, we limit our sample to the 25 MSAs with MLB teams. ${ }^{2}$ Our empirical results reflect variation in traffic consitions across cities with MLB teams.

Restricting the MSAs in the sample may lead to sample selection problems. To test for selection bias, we performed a variable addition test proposed by Wooldridge (1995). This test procedure is as follows: first, we estimated the effect of the explanatory variables in Equation (1) on selection into the sample using a separate Probit model for each year in the sample. The explanatory variables include annual MSA population, unemployment rate, and total road lane-miles. We cannot include the CBD location dummy, distance from the CBD, and the instrument (team winning percentage) because these variables are equal to zero when an MSA does not have a MLB team. For each model, we estimated the inverse Mills ratio (IMR). Next, we included the IMR in the main empirical model, Equation (1)and performed a statistical significance test on the parameter estimate on the IMR. This test failed to reject the null hypothesis that the parameter estimate is equal to zero. In this case, the fixed effects-2SLS estimator can address the sample selection bias (Wooldridge, 1995; Semykina and Wooldridge, 2010).

Another endogeneity concern lies in possible unobservable heterogeneity within MSAs with MLB teams when attendance at MLB games is correlated with unobservable factors affecting local traffic conditions. Larger cities tend to have a larger traffic demand and larger stadiums, and may also be associated with unobserved heterogeneity such as the presence of consumption amenities

\footnotetext{
${ }^{2}$ Our sample contains 25 MSAs because some cities have more than one team. We also have an unbalanced panel, as some cities attracted teams in the sample period.
} 
which can affect traffic demand. To deal with this problem, we use the winning percentage for each MLB team in each season as an instrument for MLB attendance. Team winning percentage is highly correlated with attendance, but primarily reflects the quality of the team relative to the rest of the league and random factors occurring on the field. Team success should be uncorrelated with unobservable factors affecting traffic outcomes in a metropolitan area in any year. The first-stage regression associated with Equation (1), using winning percentage as an instrument, is

$$
M L B a t t_{i t}=\widetilde{\alpha}+\widetilde{\beta}_{1} w p g 1_{i t}+\widetilde{\beta}_{2} w p g 2_{i t}+\widetilde{\gamma}^{\prime} X_{i t}+\widetilde{\lambda}_{t}+\widetilde{u}_{i t}
$$

where $w p g 1_{i t}$ indicates the MLB team's winning percentage in city $i$ in season $t$. Note that we include two winning percentage variables for Chicago, Los Angeles, New York and San Francisco, which all have two MLB teams. The IV estimator, two-stage least squares, uses the predicted value from Equation (2) in place of actual attendance in Equation (1). If the instrument is valid, the IV results have a causal interpretation; if the parameter estimate of interest is statistically different from zero in the IV model, then attendance at MLB games causes changes in traffic outcomes in metropolitan areas with MLB teams.

\section{Results}

Table 2 contains parameter estimates and other regression diagnostic statistics from Equation (1) using both the least squared dummy variable (LSDV) estimator (a two-way fixed effects model including both metropolitan area specific effects and year fixed effects) and the IV estimator using MLB team winning percentage as an instrument, using average daily vehicle-miles traveled on all roads (first two columns) and annual vehicle-hours of delay in a metropolitan area (second two columns) as the dependent variables. Estimated standard errors are cluster-corrected at the MSA level and account for MSA level heteroscedasticity. The results in columns (1) and (3) use the LSDV estimator and results in columns (2) and (4) use the IV estimator.

The LSDV parameter estimates in column (1) generally have the signs predicted by the VMT model above. Larger cities have more DVMT, other things equal. Cities with more miles of roads have more DVMT, which confirms the results reported by Duranton and Turner (2011), the 
Table 2: Regression Results, Dependent Variables: Miles Traveled and Delay

\begin{tabular}{lrrrr}
\hline Dependent Variable & \multicolumn{2}{c}{ Average Daily } & \multicolumn{2}{c}{ Annual } \\
& Vehicle-Miles Traveled & \multicolumn{2}{c}{ Vehicle-Hours of Delay } \\
Model & $(1)$ LSDV & $(2)$ IV & $(3)$ LSDV & $(4)$ IV \\
\hline MLB attendance (000) & $1.322^{*}$ & $1.749^{* *}$ & $10.74^{* *}$ & $9.913^{* *}$ \\
& $(0.753)$ & $(0.818)$ & $(4.254)$ & $(3.910)$ \\
Population (000) & $15.26^{* * *}$ & $15.18^{* * *}$ & $62.85^{* * *}$ & $63.01^{* * *}$ \\
& $(2.791)$ & $(2.607)$ & $(18.11)$ & $(17.56)$ \\
Unemployment rates & -882.1 & $-870.2^{*}$ & $-5212^{* *}$ & $-5235^{* *}$ \\
& $(570.085)$ & $(527.531)$ & $(2252)$ & $(2188)$ \\
Total road miles & $0.843^{* *}$ & $0.855^{* *}$ & 0.601 & 0.578 \\
& $(0.393)$ & $(0.374)$ & $(1.574)$ & $(1.490)$ \\
Stadium in CBD & $2951^{* * *}$ & $3017^{* * *}$ & 4033 & 3904 \\
& $(926.6)$ & $(873.1)$ & $(7299)$ & $(6821)$ \\
Distance from CBD & 434.8 & 459.1 & 3441 & 3394 \\
& $(364.7)$ & $(355.2)$ & $(2194)$ & $(2079)$ \\
\hline City \& year fixed effects & $\mathrm{Y}$ & $\mathrm{Y}$ & $\mathrm{Y}$ & $\mathrm{Y}$ \\
Instrument & & MLB Win $\%$ & & MLB Win \% \\
First stage F statistic & & 79.8 & & 79.8 \\
Number of cities & 25 & 25 & 25 & 25 \\
Years & 25 & 25 & 25 & 25 \\
\hline
\end{tabular}

$* p<0.10, * * p<0.05, * * * p<0.01$

Cluster-corrected standard errors at MSA level in parentheses.

"fundamental law of road congestion." 3 The parameter estimates on the local unemployment rate variable is negative, suggesting that driving demand is cyclical, rising during expansions and falling during recessions; fewer people working in a metropolitan area means fewer people commuting to work, and lower DVMT.

The parameter estimate of interest is on the MLB attendance variable. We expect the sign of this parameter estimate to be positive; more fans in the stands at MLB games means more people driving to the game. This should increase DVMT. The results in columns (1) and (2) confirm this, both parameter estimates are positive and significantly different from zero. The size of this parameter estimate from the LSDV model suggests that each additional 1,000 people attending an MLB game increases DVMT by 1.32 vehicle-miles, on average, holding other factors constant. The average MLB team in the sample drew about 2.8 million fans to games. The parameter estimate on column (1) suggests that this number of fans attending games would increase average DVMT by

\footnotetext{
${ }^{3}$ Duranton and Turner (2011) estimate both LSDV models and IV models that treat total road miles as endogenous.
} 
3.70 million vehicle-miles, which represents an increase of about $5.2 \%$ for the average metropolitan area with an MLB team in the sample. More vehicle-miles traveled in a metropolitan area, holding the number of miles of roads constant, means more congestion on the roads in that metropolitan area. The presence of a MLB team increases traffic congestion in cities, and the more fans that attend games, the worse is the traffic congestion. This applies to all residents of the metropolitan area, not just those who attend MLB games. In this sense, the additional traffic congestion is a negative externality in cities.

The results in columns (2) use the IV estimator, and can be interpreted as causal if the instrument is valid. Table 2 reports the standard first-stage (Stock-Yogo) F-statistic for instrument strength. These statistics indicate that our instruments are valid for both models. From column (2), the parameter estimate on MLB attendance in the IV model is positive and statistically different from zero. Fans attending MLB games cause increases in DVMT in metropolitan areas. The increase caused by MLB attendance of 2.8 million, the average attendance in the sample, is $6.9 \%$, bigger than the LSDV results on Column (1).

DVMT is higher in cities with an MLB stadium located in the CBD, relative to cities where the stadium is located in the suburbs. Distance between stadiums nearby and the CBD is not associated with additional DVMT.

While the sample analyzed here contains only metropolitan areas with MLB teams, these results have implications for cities that attract a new MLB team. When a city without one attracts a new MLB team, MLB attendance in that city goes from zero to some positive amount of attendance. Since the IV results on Table 2 indicate that higher MLB attendance causes increases in DVMT and traffic congestion, going from zero attendance at MLB games to several million fans attending games would also cause increases in urban traffic. Unfortunately, we lack access to sufficient traffic data to estimate the size of this effect.

The results on Table 2 indicate that attendance at MLB games causes increased DVMT, but this does not mean that time spent in traffic also increases. The additional miles traveled to and from MLB games could occur at off-peak times, which would not affect time spent in traffic delays much. To assess the effect of MLB games on time spent in traffic delays, we estimate Equation (1) using estimated annual metropolitan area vehicle-hours of delay as the dependent variable. This variable is estimated using both DVMT and differences in traffic speed during off-peak "free flow" 
periods (late evenings and weekends) relative to traffic speed during peak periods on weekdays during the day and early evening. Like the DVMT data, the vehicle-hours of delay estimates are aggregated up from detailed data for specific roadway segments. However, these estimates are noisier than the DVMT estimates because they use data from both the HPMS (VMT) and INRIX (speed). These variables are collected in different ways by different organizations. Because of these problems, the vehicle-hours of delay variable needs to be interpreted with some caution as it may contain substantial measurement error of an unknown form because of matching issues.

Table 3: Regression Results, Dependent Variable: Interstate and Arterial Miles Traveled

\begin{tabular}{lrrrr}
\hline \multirow{2}{*}{ Dependent Variable } & \multicolumn{2}{c}{ Daily Interstate } & \multicolumn{2}{c}{ Daily Arterial Road } \\
& \multicolumn{2}{c}{ Vehicle-Miles Traveled } & \multicolumn{2}{c}{ Vehicle-Miles Traveled } \\
& $(1)$ LSDV & $(2)$ IV & $(3)$ LSDV & $(4)$ IV \\
\hline MLB attendance (000) & $0.811^{* *}$ & $0.883^{* *}$ & 0.511 & 0.866 \\
& $(0.314)$ & $(0.350)$ & $(0.492)$ & $(0.563)$ \\
Population (000) & $8.612^{* * *}$ & $8.598^{* * *}$ & $6.653^{* * *}$ & $6.586^{* * *}$ \\
& $(0.775)$ & $(0.746)$ & $(2.227)$ & $(2.060)$ \\
Unemployment rates & $-445.9^{*}$ & $-443.9^{*}$ & -436.1 & -426.3 \\
& $(254.2)$ & $(239.0)$ & $(350.7)$ & $(320.5)$ \\
Total road miles & 0.145 & 0.147 & $0.699^{* *}$ & $0.708^{* * *}$ \\
& $(0.147)$ & $(0.137)$ & $(0.286)$ & $(0.275)$ \\
Stadiums in CBD & 1227 & 1239 & $1723^{*}$ & $1778^{* *}$ \\
& $(903.0)$ & $(870.2)$ & $(892.4)$ & $(756.9)$ \\
Distance from CBD & 246.5 & 250.6 & 188.3 & 208.5 \\
& $(204.8)$ & $(197.1)$ & $(228.7)$ & $(221.8)$ \\
\hline City \& year fixed effects & $\mathrm{Y}$ & $\mathrm{Y}$ & $\mathrm{Y}$ & $\mathrm{Y}$ \\
Instrument & & MLB Win \% & & MLB Win \% \\
First stage F statistic & & 79.8 & & 79.8 \\
Number of cities & 25 & 25 & 25 & 25 \\
Years & 25 & 25 & 25 & 25 \\
\hline
\end{tabular}

$* p<0.10, * * p<0.05, * * * p<0.01$

Cluster-corrected standard errors at MSA level in parentheses.

The last two columns on Table 2 contain LSDV and IV results from Equation (1) when the dependent variable is total vehicle-hours of delay in each metropolitan area. The results in column (3), based on the LSDV estimator indicate that attendance at MLB games is associated with additional time spent in traffic delays equal to a $2 \%$ increase in time spent in delays.

The parameter estimates on the metropolitan population variable is positive and statistically different from zero in both models. This indicates that residents of more populous cities spend 
more time in traffic delays than residents of less populous cites, other things equal. The parameter estimate on the variable reflecting the total road miles in the metropolitan area is not statistically different from zero in either model. Building more roads neither increases or decreases traffic delays in a city. This is consistent with the "fundamental law of road congestion" reported by Duranton and Turner (2011), which shows that building more roads causes more VMT in a metropolitan area, with an elasticity of new road construction of about 1 . If roads increase by $1 \%$ and VMT increases by $1 \%$, traffic delays could be unchanged.

The IV results in columns (4) shows a significant relationship between MLB attendance and traffic delays. The estimated coefficient represents an increase of about $2 \%$ for the average metropolitan area with an MLB team in the sample.

Next, we disaggregate the DVMT data by interstate and arterial road VMT. Interstates are limited access divided highways; arterial roads are commonly called "surface streets". Most of the roads immediately surrounding MLB stadiums are arterial streets, but most MLB stadiums are also located near one or more interstate highways, so the effect of MLB attendance on arterial streets could differ from the effect on interstates. While all interstate road miles contain no stoplights or stop signs, arterial streets have many such traffic restrictions. State departments of transportation maintain all interstates and some arterial streets. Recall that in most cities in the sample, DVMT is about the same on interstates and arterial streets.

Table 3 shows results for both the LSDV estimator and the IV estimator when the dependent variable is defined as average DVMT on interstates (first two columns) and arterial roads (second two columns). Columns (1) and (3) use the LSDV estimator; columns (2) and (4) use the IV estimator with annual MLB team winning percentage as the instrument for attendance. The first two columns on Table 3 contain evidence that fans attending MLB games increase DVMT on interstates in metropolitan areas. Both LSDV and IV model results support this. The parameter estimates on the unemployment rate variables and the miles of road variables are not generally statistically different from zero in these models.

Last two columns on Table 3 shows results for both the LSDV estimator and the IV estimator when the dependent variable is defined as average DVMT on arterial streets. Column (3) uses the LSDV estimator and columns (4) use the IV estimator with annual MLB team winning percentage as the instrument for annual MLB attendance. 
The results on Table 3 indicate that the results on Table 3 above, which show that MLB attendance causes increases in total DVMT primarily work through VMT on interstates. The estimated parameters on the total MLB attendance variable are positive and statistically significant for both the LSDV model and the IV model in the first two columns while the estimated parameters are not significant in the last two columns on Table tab:r2. This suggests that the increase in DVMT caused by MLB games must be attributable to additional miles driven on interstates. Most fans traveling to and from MLB games travel on interstates, not arterial roads.

The other parameter estimates on Table 3 generally have the expected sign and are statistically different from zero. Metropolitan population and the total miles of roads in the metropolitan area are both associated with larger DVMT.

\section{Robustness Checks}

While we used an IV approach to address potential endogeneity in the MLB attendance variable, it is possible that additional econometric problems exist. One possible problem might come from the unbalanced sample. In this sample period, 5 cities (Denver, Miami, Phoenix, Tampa and Washington DC) either gained a new MLB team or attracted an existing team. This decision might be correlated with other unobserved factors affecting traffic in these cities. To address this problem, we perform a sensitivity test using the subsample which excludes these 5 cities. While we lose observations in this restricted sample, the results from this reduced sample will look similar to the original results if the unbalanced sample does not create any econometric problems.

Another concern arises from metropolitan areas with two teams. In our sample, four metropolitan areas (Chicago, Los Angeles, San Francisco/Oakland, and New York) have two teams throughout the sample period. The existence of two teams might affect a traffic demand in a city differently than a single team. These large metropolitan areas could also have some other unobserved features that have a different impact on traffic. To address this problem, we exclude these 4 metropolitan areas from the restricted sample. This restricted sample also helps to determine the extent to which traffic in these four large metropolitan areas drives the results.

Results from these robustness checks are shown in Table 4. On this table, only the coefficient

estimates of interest, $\hat{\beta}$ (the parameter estimate on the MLB attendance variable) and the estimated standard error on this parameter are shown using the IV estimator. The "Full 25 team MLB MSAs" 
Table 4: Robustness Checks - IV Estimator

\begin{tabular}{llr}
\hline Dependent Variable & Sample & $\hat{\beta} /$ s. e. \\
\hline Average Daily Vehicle-Miles Traveled & Full 25 MLB MSAs & $1.749^{* *}$ \\
& & $(0.818)$ \\
& Balanced Sample & $1.867^{* *}$ \\
& & $(0.792)$ \\
& Excluding cities with two teams & $1.947^{* * *}$ \\
& & $(0.696)$ \\
\hline Annual vehicle-hours of delay & Full 25 MLB MSAs & $9.913^{* *}$ \\
& & $(3.910)$ \\
& Balanced Sample & $10.16^{* * *}$ \\
& Excluding cities with two teams & $(3.712)$ \\
& & $(1.886$ \\
& Full 25 MLB MSAs & $0.883^{* *}$ \\
\hline Daily Interstate Vehicle-Miles Traveled & & $(0.350)$ \\
& Balanced Sample & $1.001^{* * *}$ \\
& & $(0.326)$ \\
& Excluding cities with two teams & $1.069^{* * *}$ \\
& & $(0.340)$ \\
\hline Daily Arterial Road Vehicle-Miles Traveled & Full 25 MLB MSAs & 0.866 \\
& & $(0.563)$ \\
& Balanced Sample & 0.866 \\
& & $(0.554)$ \\
& & $0.877^{* *}$ \\
& & $(0.442)$ \\
\hline
\end{tabular}

$* p<0.10, * * p<0.05, * * * p<0.01$

Cluster-corrected standard errors at MSA level in parentheses. 
sample reproduces the original results from Tables 2 and 3; the "Balanced Sample" represents results using only cities home to an MLB team for the entire period. The "Excluding cities with two teams" sample represents results excluding the four large metropolitan areas with two MLB teams. The results look similar to our main results both qualitatively and quantitatively. One difference is the model using annual vehicle-hours of delay as the dependent variable. The effect of MLB attendance on annual vehicle hours of delay loses statistical significance when excluding the four large metropolitan areas with two teams. This might indicate that the estimated effects on hours of delay are driven by these large metropolitan areas. Also, the parameter estimate for arterial roads VMT becomes statistically significant when excluding these four larger metropolitan areas.

The results reported on Tables 2 and 3 are generally robust to these sample restrictions. Even when focusing only on metropolitan areas with one MLB team, vehicle-miles traveled in metropolitan areas increases with attendance at MLB games.

\section{Conclusions}

This paper examines the extent to which attendance at MLB games increases traffic volume and congestion in host cities. Using traffic volume and congestion data from the 2015 Urban Mobility Scorecard for 25 US cities with MLB teams from 1990 to 2014, we empirically estimate the effect of annual MLB attendance on traffic volume and congestion after controlling for factors that affect demand and supply of driving, economic conditions, and unobservable city and year heterogeneity. Our main results suggest that each additional 1,000 fans attending MLB games increases average daily vehicle-miles traveled by 1.749 miles, which implies a $6.9 \%$ increase in total annual vehiclemiles traveled in a city with annual MLB attendance of 2.8 million, the sample average. This paper also finds a weak evidence of an effect of MLB attendance on total annual hours of delay from traffic congestion, although this may be driven by traffic conditions in the four larger metropolitan areas with two MLB teams in the sample.

These results reflect only attendance at MLB games. The cities in the sample also host National Football League, National Basketball Association, and National Hockey League games. Attendance at these games is substantial, and many of the games in these leagues also occur on weeknights. 
If fans driving to these games have a similar effect on urban traffic, then the overall effect of professional sports on urban VMT and road congestion is substantially larger than the evidence developed here suggests.

Negative congestion externalities are often overlooked when assessing the net local effect of public subsidization of sports facility construction, which is common in the US. Our results suggest that significant increases game-related traffic exist in cities with MLB teams, which leads to substantial social costs. While professional sports may contribute to vibrancy in urban areas, they may not lead to reductions in VMT and greenhouse gas emissions like other factors analyzed by Holian and Kahn (2012). Therefore, urban policymakers contemplating a subsidy for a new professional sports facility, or attracting a team from another city to increase local vibrancy, should take into account this negative consequence.

While this paper is the first to estimate the effect of game attendance on urban traffic volume, we could not quantify this effect in monetary terms. Additional research exploring the social costs created by increased game-related traffic are clearly needed. Also, using aggregated city-level and annual data might obscure the underlying effects of MLB games on traffic volume. It is possible that MLB games create traffic jams in areas around the stadium and reduce traffic in other parts of the city. It is also possible that 81 home games (or around 55 home games on weekdays) are not sufficient to affect outcomes aggregated across a calendar year over entire metropolitan areas. These problems could be addressed by analyzing micro-level data in future research. 


\section{References}

Albouy, D. and Lue, B. (2015). Driving to opportunity: Local rents, wages, commuting, and sub-metropolitan quality of life. Journal of Urban Economics, 89:74-92.

Bureau of the Census, U. S. (1985). 1982 Census of Retail Trade: Major retail centers in standard metropolitan statistical areas. Number v. 1 in 1982 Census of Retail Trade: Major Retail Centers in Standard Metropolitan Statistical Areas. U.S. Department of Commerce, Bureau of the Census.

Chase, J. and Healey, M. (1995). The spatial externality effects of football matches and rock concerts: The case of Portman Road Stadium, Ipswich, Suffolk. Applied Geography, 15(1):18-34.

Coates, D. and Humphreys, B. R. (2003). The effect of professional sports on earnings and employment in the services and retail sectors in US cities. Regional Science and Urban Economics, $33(2): 175-198$.

Coates, D., Humphreys, B. R., et al. (2008). Do economists reach a conclusion on subsidies for sports franchises, stadiums, and mega-events? Econ Journal Watch, 5(3):294-315.

Cotti, C. and Tefft, N. (2011). Decomposing the relationship between macroeconomic conditions and fatal car crashes during the great recession: alcohol-and non-alcohol-related accidents. The BE Journal of Economic Analysis $\&$ Policy, 11(1).

Duranton, G. and Turner, M. A. (2011). The fundamental law of road congestion: Evidence from US cities. The American Economic Review, 101(6):2616-2652.

He, M. M. (2016). Driving through the great recession: Why does motor vehicle fatality decrease when the economy slows down? Social Science $\&$ Medicine, 155:1-11.

Holian, M. J. and Kahn, M. E. (2012). The impact of center city economic and cultural vibrancy on greenhouse gas emissions from transportation. Research Report 11-13, Mineta Transportation Institute, San Jose, CA.

Huang, H. and Humphreys, B. R. (2014). New sports facilities and residential housing markets. Journal of Regional Science, 54(4):629-663. 
Humphreys, B. R. and Zhou, L. (2015). Sports facilities, agglomeration, and public subsidies. Regional Science and Urban Economics, 54:60-73.

Humphreys, D., Mason, C., and Pinch, S. (1983). The externality fields of football grounds: a case study of the Dell, Southampton. Geoforum, 14(4):401-411.

Krueger, A. B., Kahneman, D., Schkade, D., Schwarz, N., and Stone, A. A. (2009). National time accounting: The currency of life. In Kreuger, A. B., editor, Measuring the subjective well-being of nations: National accounts of time use and well-being, pages 9-86. University of Chicago Press.

Lasley, P., Lomax, T., Eisele, W., and Schrank, D. (2014). Developing a total peak period travel time performance measure: An updated concept paper. Transportation Research Record: Journal of the Transportation Research Board, (2420):15-22.

Pyun, H. and Hall, J. C. (2016). Does the presence of professional football cause crime in a city? evidence from Pontiac, Michigan. Working Paper 16-02, West Virginia University.

Rappaport, J. (2016). Productivity, congested commuting, and metro size. Research Working Paper RWP 16-3, Federal Reserve Bank of Kansas City.

Salon, D., Boarnet, M. G., Handy, S., Spears, S., and Tal, G. (2012). How do local actions affect VMT? a critical review of the empirical evidence. Transportation research part D: transport and environment, 17(7):495-508.

Semykina, A. and Wooldridge, J. M. (2010). Estimating panel data models in the presence of endogeneity and selection. Journal of Econometrics, 157(2):375-380.

Small, K. A. and Verhoef, E. T. (2007). The economics of urban transportation. Routledge.

Wooldridge, J. M. (1995). Selection corrections for panel data models under conditional mean independence assumptions. Journal of Econometrics, 68(1):115-132. 